\title{
Hidrogeomorfometria da microbacia do rio Paraíso: informações para auxiliar o ma- nejo dos recursos naturais na Amazônia Ocidental
}

\author{
Hydrogeomorphometry of the Paraíso river microbasin: information to assist the management of \\ natural resources in the Western Amazon
}

Hidrogeomorfometría de la microcuenca del río Paraíso: información para ayudar al manejo de los recursos naturales en la Amazonía Occidental

\author{
Marcelo Medeiros de Lima \\ ORCID: https://orcid.org/0000-0002-3347-8815 \\ Universidade Federal do Amazonas, Brasil \\ E-mail: delima.job@gmail.com \\ Miquel Victor Batista Donegá \\ ORCID: https://orcid.org/0000-0003-4904-5552 \\ Universidade Federal do Amazonas, Brasil \\ E-mail: miquel@ufam.edu.br \\ Tiago Way Serrão de Souza \\ ORCID: https://orcid.org/0000-0003-3787-5014 \\ Universidade Federal do Amazonas, Brasil \\ E-mail: wayserrao@gmail.com \\ Mylena Rego Panza \\ ORCID: https://orcid.org/0000-0002-3756-8017 \\ Universidade Federal do Amazonas, Brasil \\ E-mail: panzamylena@gmail.com \\ Fabrício Matheus Pimenta Pacheco \\ ORCID: https://orcid.org/0000-0002-4705-7034 \\ Universidade Federal do Amazonas, Brasil \\ E-mail: fabriciomatheus95@gmail.com \\ Wanderson Cleiton Schmidt Cavalheiro \\ ORCID: htts://porcid.org/0000-0003-1356-8511 \\ Cavalheiro Engenharia Rural e Empresarial Ltda, Brasil \\ E-mail: engflo.ro@gmail.com \\ Francisco Adilson dos Santos Hara \\ ORCID: https://orcid.org/0000-0002-3215-953X \\ Universidade Federal do Amazonas, Brasil \\ E-mail: fhara@ufam.edu.br \\ Jhony Vendruscolo \\ ORCID: https://orcid.org/0000-0003-3043-0581 \\ Universidade Federal do Amazonas, Brasil \\ E-mail: jhonyvendruscolo@gmail.com
}

\begin{abstract}
Resumo
A análise das características da paisagem é o primeiro passo para o planejamento e a gestão adequada dos recursos naturais. Em face ao exposto, o presente trabalho tem como objetivo fornecer informações sobre as características da paisagem na microbacia do rio Paraíso, Amazônia Ocidental, Brasil. As informações estão associadas aos parâmetros geométricos, topográficos e hidrográficos, e dinâmica de cobertura do solo, e foram obtidas com o uso dos softwares QGIS, Google Earth e TrackMaker Free, imagens altimétricas (satélite ALOS) e de cobertura do solo (satélites Landsat 5 e Landsat 8), e dados da literatura. A microbacia do rio Paraíso tem área de $50,76 \mathrm{~km}^{2}$, forma alongada, baixa suscetibilidade a enchentes, altitudes entre 234 e $458 \mathrm{~m}$, predomínio de relevo ondulado, rio de porte médio, padrão de drenagem dendrítico de $5^{\mathrm{a}}$ ordem, alta densidade de nascentes, densidade de drenagem muito alta, canal principal sinuoso, baixo coeficiente de manutenção e alto tempo de concentração. No período de 1984 a 2020, a agropecuária avançou sobre as áreas de floresta nativa, chegando a ocupar $80,32 \%$ da área da microbacia e 64,21\% da área de zona ripária no último ano. A microbacia tem elevado potencial para o desenvolvimento de sistemas agropecuários, contudo são recomendadas adoções de práticas de manejo conservacionista do solo e da água, a manutenção e/ou recuperação das florestas nativas protegidas por Lei, e a integração do componente arbóreo nos sistemas econômicos (ex: sistemas agroflorestais e agrosilvipastoris). Essas recomendações visam conciliar o desenvolvimento econômico e a conservação dos recursos naturais, ambos essenciais para o desenvolvimento sustentável da região.
\end{abstract}

Palavras-chave: Sensoriamento remoto; Recursos naturais; Planejamento ambiental; Desenvolvimento sustentável. 


\begin{abstract}
The analysis of the characteristics of the landscape is the first step in the planning and proper management of natural resources. In view of the above, this study aims to provide information on landscape characteristics in the Paraíso river microbasin, Western Amazon, Brazil. The information is associated with geometric, topographic and hydrographic parameters, and ground cover dynamics, and was obtained using the QGIS, Google Earth and TrackMaker Free software, altimetric images (ALOS satellite) and ground cover (Landsat 5 and Landsat 8 satellites), and data from the literature. The Paraíso river microbasin has an area of $50.76 \mathrm{~km}^{2}$, elongated shape, low susceptibility to flooding, altitudes between 234 and $458 \mathrm{~m}$, predominance of wavy relief, medium sized river, 5th order dendritic drainage pattern, high spring density, very high drainage density, meandering main channel, low maintenance coefficient and high concentration time. In the period from 1984 to 2020, agriculture advanced over the areas of native forest, reaching $80.32 \%$ of the microbasin area and $64.21 \%$ of the riparian area in the last year. The microbasin has a high potential for the development of agricultural systems, however it is recommended to adopt conservationist soil and water management practices, the maintenance and / or recovery of native forests protected by law, and the integration of the tree component in economic systems ( ex: agroforestry and agrosilvipastoral systems). These recommendations aim to reconcile economic development and the conservation of natural resources, both essential for the sustainable development of the region.
\end{abstract}

Keywords: Remote sensing; Natural resources; Environmental planning; Sustainable development.

\title{
Resumen
}

El análisis de las características del paisaje es el primer paso en la planificación y gestión adecuada de los recursos naturales. En vista de lo anterior, el presente trabajo tiene como objetivo brindar información sobre la características del paisaje en la microcuenca del río Paraíso, Amazonia Occidental, Brasil. La información está asociada a parámetros geométricos, topográficos e hidrográficos, y dinámica de cobertura del suelo, y se obtuvo mediante el software QGIS, Google Earth y TrackMaker Free, imágenes altimétricas (satélite ALOS) y cobertura del suelo (satélites Landsat 5 y Landsat 8), y datos de la literatura. La microcuenca del río Paraíso tiene un área de 50,76 km², forma alargada, baja susceptibilidad a inundaciones, altitudes entre 234 y $458 \mathrm{~m}$, predominio de relieve ondulado, río de tamaño medio, patrón de drenaje dendrítico de 5 orden, alta densidad de manantiales, densidad de drenaje muy alta, canal principal sinuoso, bajo coeficiente de mantenimiento y alto tiempo de concentración. En el período de 1984 a 2020, la agricultura avanzó sobre las áreas de bosque nativo, alcanzando el 80,32\% del área de la microcuenca y el 64,21\% del área ribereña en el último año. La microcuenca tiene un alto potencial para el desarrollo de sistemas agrícolas, sin embargo se recomienda adoptar prácticas conservacionistas de manejo de suelos y aguas, el mantenimiento y / o recuperación de bosques nativos protegidos por ley, y la integración del componente arbóreo en los sistemas económicos (ej.: sistemas agroforestales y agrosilvopastoriles). Estas recomendaciones tienen como objetivo conciliar el desarrollo económico y la conservación de los recursos naturales, ambos esenciales para el desarrollo sostenible de la región.

Palabras clave: Teledetección; Recursos naturales; Planificación ambiental; Desenvolvimiento sustentable.

\section{Introdução}

A microbacia do rio Paraíso tem grande relevância ambiental, social e econômica, por estar inserida na bacia do rio Guaporé, sub-bacia do rio Vermelho (SEDAM, 2002), e abranger 52 estabelecimentos agropecuários privados (INCRA, 2019). O ecótono formado pela parte montante dos rios Guaporé e Paraguai forma um corredor ecológico que conecta as regiões biogeográficas da Amazônia e do Pantanal, reconhecidas pela alta importância para a biodiversidade (Silva, et al., 2015). Os estabelecimentos agropecuários privados têm papel de destaque na economia da região Norte brasileira, contudo, constatam-se limitações ao desenvolvimento destes estabelecimentos, em função de vários fatores que incluem questões ambientais, atraso tecnológico e falta de assistência técnica (Castro, 2013). Neste contexto, constata-se a necessidade de planejar adequadamente a gestão dos recursos naturais para conciliar o desenvolvimento sustentável na região.

A eficiência da gestão dos recursos naturais depende da qualidade das informações inseridas no planejamento, e estão relacionadas com as características ambientais, incluindo uso e ocupação do solo. Estas informações permitem quantificar os recursos naturais disponíveis na região, delimitar áreas prioritárias para a conservação destes recursos, analisar o potencial agropecuário, e selecionar as práticas de manejo do solo e água mais eficientes para mitigar os impactos das atividades antrópicas no meio ambiente (Silva, et al., 2021).

Informações de qualidade podem ser obtidas com baixo custo financeiro e tempo relativamente curto, por meio de geotecnologias, mesmo em áreas com grandes dimensões (Soares, et al., 2019). Em função destas vantagens essa metodologia tem se tornado cada vez mais utilizada nos últimos anos, como pode ser visto nos trabalhos realizados nas microbacias dos rios 
Jacuri (Panza, et al., 2020), Alto Rio Escondido (Vendruscolo, et al., 2020a), Médio Rio Escondido (Vendruscolo, et al., 2020b), Gavião (Donegá, et al., 2021), Três Galhos (Silva, et al., 2021) e Mutum (Souza, et al., 2021).

Em face ao exposto, o trabalho tem como objetivo disponibilizar informações sobre as características da paisagem e analisar a dinâmica de ocupação do solo na microbacia do rio Paraíso, Amazônia Ocidental, Brasil.

\section{Metodologia}

A microbacia do rio Paraíso está inserida na sub-bacia do rio Vermelho, localizada no município de Colorado D’Oeste (Figura 1). Esta região tem clima do tipo Monção, temperaturas médias entre 24 e $26^{\circ} \mathrm{C}$ (Alvares, et al., 2013), e precipitação média anual de 1.728,9 a 1.843,7 mm, que ocorrem principalmente nos meses de novembro a março (Franca, 2015).

Figura 1. Localização da microbacia do rio Paraíso, Amazônia Ocidental, Brasil.

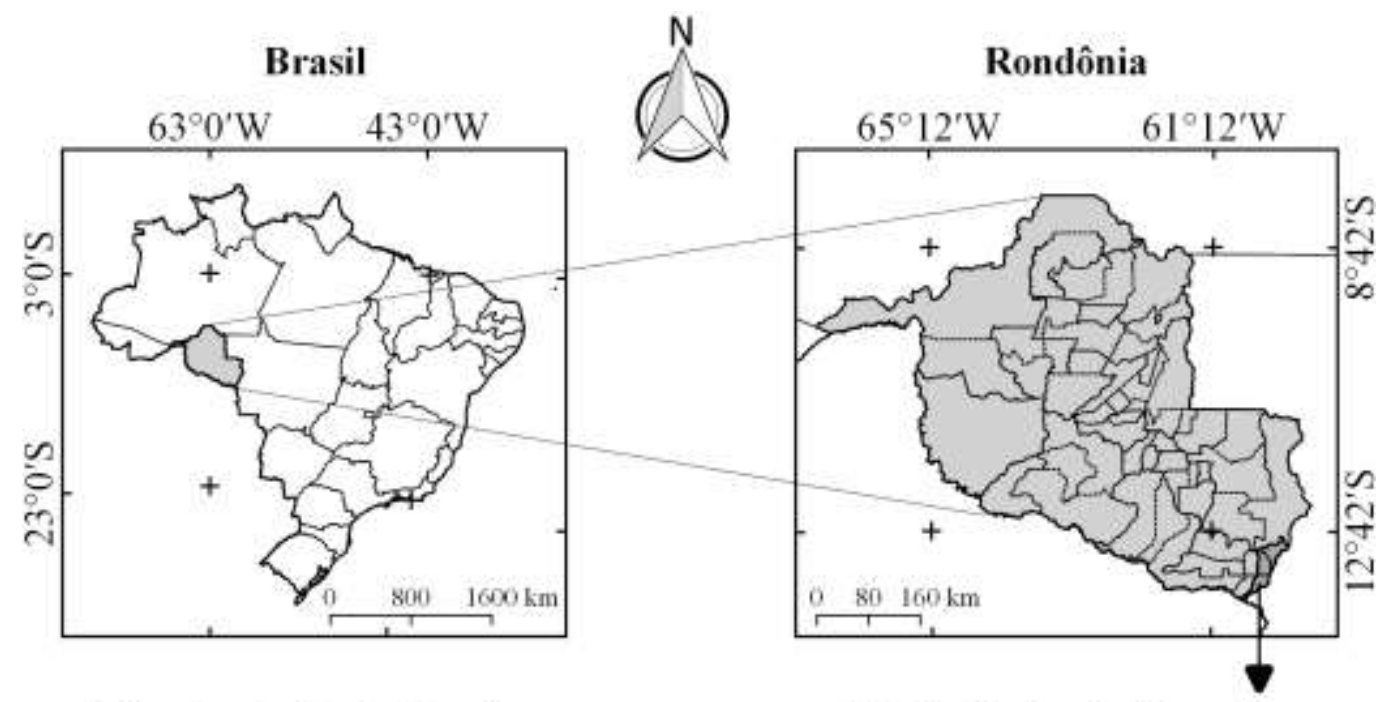

Microbacia do rio Paraíso
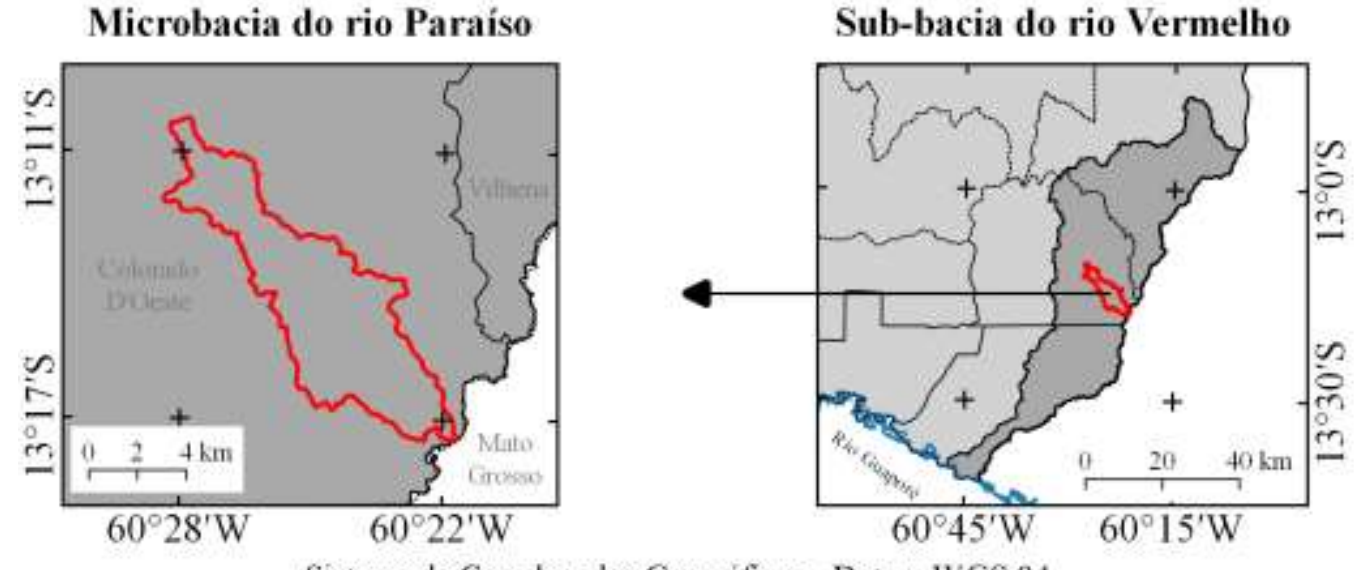

Sistema de Coordenadas Geográficas - Datum WGS 84

Fonte: Autores.

\subsection{Características da paisagem}

As características da paisagem estão associadas aos parâmetros geométricos (área, perímetro, fator de forma, índice de circularidade e coeficiente de compacidade), topográficos (altitude e declividade), hidrográficos (padrão da rede de drenagem, ordem dos rios, densidade de nascentes, densidade de drenagem, coeficiente de manutenção, índice de sinuosidade e tempo de concentração), uso e cobertura do solo. Para a aquisição das informações e elaboração dos mapas, foram utilizados os softwares QGIS 2.10.1 (Pisa), Google Earth e TrackMaker Free (Versão 13.9.596), imagens dos satélites ALOS (ASF, 2017), Landsat 5 e 
Landsat 8, e equações disponíveis na literatura. Portanto, inicialmente foi utilizado a metodologia quantitativa para aquisição de dados numéricos, e em seguida a metodologia qualitativa para interpretar os dados numéricos e elaborar ideias a respeito de cada parâmetro, corroborando com Pereira et al. (2018). Esse trabalho foi executado em cinco etapas:

\section{$1^{\mathrm{a}}$ Etapa: Características geométricas}

Área e perímetro: a princípio realizou-se a delimitação da microbacia de forma automática, utilizando a ferramenta TauDEM

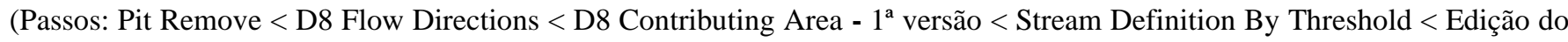
ponto de exutório < D8 Contributing Area - $2^{\mathrm{a}}$ versão) e imagens altimétricas do satélite AlOS, com resolução espacial de 12,5 m. $\mathrm{O}$ arquivo matricial, gerado no TauDEM, foi transformado para o formato vetorial (ferramenta "poligonizar"), em seguida, dissolvido (ferramenta "dissolver"), suavizado (ferramenta "simplificar geometria") e ajustado no software Google Earth, considerando as características da rede de drenagem e relevo. Após isso, foram calculados a área e o perímetro com a ferramenta "calculadora de campo".

Os parâmetros fator de forma, índice de circularidade e coeficiente de compacidade, foram calculados com as equações 1 (Villela \& Mattos, 1975), 2 (Christofoletti, 1980) e 3 (Villela \& Mattos, 1975), e comparados com dados da literatura (Tabela $1)$.

$$
F=\frac{A}{L^{2}}
$$

Onde: $\mathrm{F}$ = fator de forma; $\mathrm{A}=$ área da microbacia $\left(\mathrm{km}^{2}\right) ; \mathrm{L}=$ comprimento do eixo da microbacia $(\mathrm{km})$.

$$
\text { Ic }=\frac{12,57 x A}{P^{2}}
$$

Onde: $\mathrm{Ic}=$ índice de circularidade; $\mathrm{A}=$ área da microbacia $\left(\mathrm{km}^{2}\right) ; \mathrm{P}=$ perímetro da microbacia $(\mathrm{km})$.

$$
K c=0,28 \times \frac{P}{\sqrt{ } A}
$$

Onde: $\mathrm{Kc}=$ coeficiente de compacidade; $\mathrm{A}=$ área da microbacia $\left(\mathrm{km}^{2}\right) ; \mathrm{P}=$ perímetro da microbacia $(\mathrm{km})$.

Tabela 1. Classificação dos parâmetros geométricos: fator de forma, índice de circularidade e coeficiente de compacidade.

\begin{tabular}{ccc}
\hline Parâmetro & Limite & Classe \\
\hline \multirow{2}{*}{ Fator de forma $^{1}$} & $<0,50$ & Não sujeito a inundações \\
& $0,50-0,75$ & Tendência média a inundações \\
& $0,76-1,00$ & Sujeito a inundações \\
\hline & $<0,51$ & Forma alongada \\
Índice de circularidade $^{2}$ & $0,51-0,75$ & Forma intermediária \\
& $0,76-1,00$ & Forma circular \\
\hline \multirow{2}{*}{ Coeficiente de compacidade $^{1}$} & $1,00-1,25$ & Alta propensão a inundações \\
& $1,26-1,50$ & Tendência média a inundações \\
\hline
\end{tabular}

Fonte: ${ }^{1}$ Lima Júnior, et al. (2012); ${ }^{2}$ Silva (2012). 


\section{$2^{\text {a }}$ Etapa - Características topográficas}

Altitude e declividade: as altitudes mínima e máxima foram obtidas diretamente da imagem altimétrica, e a altitude média foi mensurada com a ferramenta "estatística por zona". A declividade foi mensurada com base na imagem altimétrica, utilizando a ferramenta "Modelo Digital de Elevação", em seguida foi classificada para se obter informações sobre o relevo, influência na propagação de incêndios e aptidão à mecanização agrícola (Tabela 2).

Tabela 2. Classificação da declividade com relação ao relevo, influência na propagação de incêndios e aptidão à mecanização agrícola.

\begin{tabular}{|c|c|c|}
\hline Parâmetro & Classe & Declividade (\%) \\
\hline \multirow{6}{*}{ Relevo $^{1}$} & Plano & $0-3$ \\
\hline & Suave ondulado & $3-8$ \\
\hline & Ondulado & $8-20$ \\
\hline & Forte ondulado & $20-45$ \\
\hline & Montanhoso & $45-75$ \\
\hline & Escarpado & $>75$ \\
\hline \multirow{5}{*}{ Influência na propagação de incêndios ${ }^{2}$} & Baixa & $\leq 15$ \\
\hline & Moderada & $16-25$ \\
\hline & Alta & $26-35$ \\
\hline & Muito alta & $36-45$ \\
\hline & Extremamente alta & $>45$ \\
\hline \multirow{5}{*}{ Aptidão à mecanização agrícola ${ }^{3}$} & Extremamente apta & $0-5,0$ \\
\hline & Muito apta & $5,1-10,0$ \\
\hline & Apta & $10,1-15,0$ \\
\hline & Moderadamente apta & $15,1-20,0$ \\
\hline & Não apta & $>20,0$ \\
\hline
\end{tabular}

Fonte: ${ }^{1}$ Santos, et al., (2013); ${ }^{2}$ Ribeiro, et al. (2008); ${ }^{3}$ Höfig \& Araujo-Junior (2015).

\section{$3^{\text {a }}$ Etapa - Características hidrográficas}

Rede de drenagem: inicialmente foram elaborados os rios (trilhas) com a ferramenta "adicionar caminho" do software Google Earth. As trilhas foram salvas em formato KML (Keyhole Markup Language) e unidas no software TrackMaker Free com a ferramenta "Lápis", para formar a rede de drenagem, em seguida o arquivo foi convertido para o formato Shapefile (SHP).

Padrão da rede de drenagem: foi identificado por meio de comparação visual entre a distribuição espacial da rede de drenagem da microbacia em estudo e um catálogo contendo os principais padrões de drenagem, disponibilizado por Parvis (1950).

Ordem dos rios: classificado com a ferramenta "Strahler", onde as nascentes originam os rios de $1^{\text {a }}$ ordem, o encontro de dois rios de $1^{\mathrm{a}}$ ordem forma um rio de $2^{\mathrm{a}}$ ordem, o encontro de dois rios de $2^{\mathrm{a}}$ ordem forma um rio de $3^{\mathrm{a}}$ ordem, e assim sucessivamente (Strahler, 1954).

Densidade de nascentes: indica o potencial hídrico da região, quanto mais alto o valor, maior o potencial (Cherem, et al., 2020). Esse parâmetro foi mensurado com a equação 4 (Christofoletti, 1980).

$$
D n=\frac{N}{A}
$$


Onde: $\mathrm{Dn}=$ densidade de nascentes (nascentes $\left.\mathrm{km}^{-2}\right) ; \mathrm{N}=$ número de nascentes; $\mathrm{A}=$ área da microbacia $\left(\mathrm{km}^{2}\right)$.

Densidade de drenagem: representa o grau de desenvolvimento e a eficiência do sistema de drenagem da microbacia (Villela \& Mattos, 1975), e foi calculado com a equação 5 (Horton, 1932).

$$
D d=\frac{L}{A}
$$

Onde: $\mathrm{Dd}=$ densidade de drenagem $\left(\mathrm{km} \mathrm{km}^{-2}\right) ; \mathrm{L}=$ comprimento da rede de drenagem $(\mathrm{km}) ; \mathrm{A}=$ área da microbacia $\left(\mathrm{km}^{2}\right)$.

Coeficiente de manutenção: corresponde a área necessária para a microbacia manter perene cada metro de rio, e foi calculado com a equação 6 (Santos, et al., 2012).

$$
C m=\frac{1}{D d} x 1000
$$

Onde: $\mathrm{Cm}=$ coeficiente e manutenção $\left(\mathrm{m}^{2} \mathrm{~m}^{-1}\right) ; \mathrm{Dd}=$ densidade de drenagem $\left(\mathrm{km} \mathrm{km}^{-2}\right)$.

Índice de sinuosidade: este parâmetro está relacionado com a velocidade do fluxo hídrico, sendo observado redução da velocidade com o aumento da sinuosidade, e foi calculado com a equação 7 (Villela \& Mattos, 1975).

$$
I s=\frac{L-D v}{L} x 100
$$

Onde: Is = índice de sinuosidade $(\%) ; \mathrm{L}=$ comprimento do canal principal $(\mathrm{km}) ; \mathrm{Dv}=$ distância vetorial do canal principal $(\mathrm{km})$.

Tempo de concentração: estabelece o tempo necessário para que toda a área da microbacia contribua com o fluxo hídrico, e foi mensurado com a equação 8 (Kirpich, 1940, citado por Targa, et al., 2012).

$$
T c=57 x\left(\frac{L^{3}}{H}\right)^{0,385}
$$

Onde: $\mathrm{Tc}=$ tempo de concentração (minutos); $\mathrm{L}=$ comprimento do talvegue principal $(\mathrm{km}) ; \mathrm{H}=$ desnível entre a parte mais elevada e a seção de controle (m).

Os parâmetros ordem dos rios, densidade de nascentes, densidade de drenagem e índice de sinuosidade foram classificados de acordo com a literatura (Tabela 3). 
Tabela 3. Classificação das características hidrográficas.

\begin{tabular}{|c|c|c|c|}
\hline Parâmetro & Unidade & Limite & Classe \\
\hline Ordem dos rios ${ }^{1}$ & Unidades & $\begin{array}{l}1-3 \\
4-6 \\
>6\end{array}$ & $\begin{array}{l}\text { Riachos pequenos } \\
\text { Riachos médios } \\
\text { Rios grandes }\end{array}$ \\
\hline Ordem dos rios ${ }^{2}$ & Unidades & $\begin{array}{c}1 \\
2 \\
3 \\
\geq 4\end{array}$ & $\begin{array}{l}\text { Improvável habitat de peixes } \\
\text { Baixas condições para habitação } \\
\text { Moderadas condições para habitação } \\
\text { Elevadas condições para habitação }\end{array}$ \\
\hline Densidade de nascentes ${ }^{3}$ & Nascentes $\mathrm{km}^{-2}$ & $\begin{array}{c}<3 \\
3-7 \\
7-15 \\
>15\end{array}$ & $\begin{array}{l}\text { Baixa } \\
\text { Média } \\
\text { Alta } \\
\text { Muito alta }\end{array}$ \\
\hline Densidade de drenagem ${ }^{4}$ & $\mathrm{~km} \mathrm{~km}^{-2}$ & $\begin{array}{c}<0,50 \\
0,50-2,00 \\
2,00-3,50 \\
>3,50\end{array}$ & $\begin{array}{l}\text { Baixa } \\
\text { Média } \\
\text { Alta } \\
\text { Muito alta }\end{array}$ \\
\hline Índice de sinuosidade ${ }^{5}$ & $\%$ & $\begin{array}{c}<20 \\
20-29 \\
30-39 \\
40-50 \\
>50\end{array}$ & $\begin{array}{c}\text { Muito reto } \\
\text { Reto } \\
\text { Divagante } \\
\text { Sinuoso } \\
\text { Muito sinuoso }\end{array}$ \\
\hline
\end{tabular}

Fonte: ${ }^{1}$ Vannote, et al. (1980); ${ }^{2}$ Adaptado de Fairfull \& Witheridge (2003); ${ }^{3}$ Lollo (1995); ${ }^{4}$ Beltrame (1994); ${ }^{5}$ Romero, Formiga \& Marcuzzo (2017).

\section{Etapa - Dinâmica da cobertura do solo}

Para a análise da dinâmica de cobertura do solo foram usadas imagens registradas pelos satélites Landsat 5 (1984) e Landsat 8 (2020) (INPE, 2020), escolhidas entre os meses de julho a setembro por conta da ausência de nuvens e melhor qualidade das imagens (Tabela 4).

Tabela 4. Características das imagens dos satélites Landsat 5 e Landsat 8, utilizadas na produção do índice de desmatamento na microbacia do rio Paraíso.

\begin{tabular}{|c|c|c|c|c|c|c|c|c|}
\hline \multirow[b]{2}{*}{ Ano } & \multirow[b]{2}{*}{ Satélite } & \multirow[b]{2}{*}{ Sensor } & \multirow[b]{2}{*}{ Banda } & \multicolumn{4}{|c|}{ Resolução } & \multirow{2}{*}{$\begin{array}{c}\text { Ór- } \\
\text { bita/Ponto }\end{array}$} \\
\hline & & & & $\begin{array}{c}\text { Espectral } \\
(\mu \mathrm{m})\end{array}$ & $\begin{array}{c}\text { Espacial } \\
(\mathbf{m})\end{array}$ & $\begin{array}{c}\text { Radiométrica } \\
\text { (bits) }\end{array}$ & $\begin{array}{c}\text { Temporal } \\
\text { (dias) }\end{array}$ & \\
\hline 1984 & Landsat 5 & $\mathrm{TM}$ & $\begin{array}{l}3 \\
4 \\
5\end{array}$ & $\begin{array}{c}0,63-0,69 \\
0,76-0,90 \\
1,55-1,75\end{array}$ & 30 & (2) & 16 & $230 / 69$ \\
\hline 2020 & Landsat 8 & OLI & $\begin{array}{l}4 \\
5 \\
6 \\
\end{array}$ & $\begin{array}{l}0,64-0,67 \\
0,85-0,88 \\
1,57-1,65 \\
\end{array}$ & 30 & 16 & 16 & $230 / 69$ \\
\hline
\end{tabular}

$\mathrm{TM}=$ Thematic Mapper; OLI = Operational Land Imager.

A cobertura do solo é composta principalmente por três classes, identificadas como água, agropecuária e floresta nativa. Estas coberturas foram classificadas utilizando quatro passos:

$1^{\circ}$ Passo: Cálculo do Índice de Vegetação por Diferença Normalizada (IVDN), com a equação 9.

$$
\mathrm{IVDN}=(\mathrm{IP}-\mathrm{V}) /(\mathrm{IP}+\mathrm{V})
$$


Onde: IP = Infravermelho Próximo (B4 = Landsat 5; B5 = Landsat 8); V = vermelho (B3 = Landsat 5; B4 = Landsat 8).

$2^{\circ}$ Passo: coleta de 15 amostras de pixel em cada classe de cobertura do solo, totalizando 45 amostras de pixels em cada imagem IVDN.

$3^{\circ}$ Passo: divisão da imagem IVDN em classes com a ferramenta "slicer", e conversão da imagem matricial gerada para formato vetorial, com a ferramenta "poligonizar".

$4^{\circ}$ Passo: comparação da imagem classificada com a imagem falsa cor (R5G4B3 para o Landsat 5, e R6G5B4 para o Landsat 8), para validar a classificação.

A análise de cobertura do solo foi realizada na microbacia e em sua zona ripária. A segunda foi delimitada com a ferramenta "Buffer", considerando $50 \mathrm{~m}$ de raio para as nascentes de $30 \mathrm{~m}$ de margem para os rios, conforme estabelece o Código Florestal Brasileiro (Brasil, 2012).

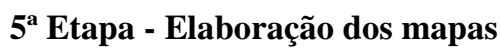

Para elaboração do mapa foi utilizado a ferramenta "Novo Compositor de Impressão" no software QGIS, e como referência, o Sistema de Coordenadas Geográficas e Datum WGS 84.

\section{Resultados e Discussão}

\subsection{Características geométricas}

A microbacia tem área de 50,76 km², perímetro de 49,04 km, fator de forma de 0,16, índice de circularidade de 0,27e coeficiente de compacidade correspondente a 1,93. Logo, a microbacia tem forma alongada e não é suscetível a enchentes. Resultados semelhantes podem ser observados em outras microbacias que pertencem a bacia do rio Guaporé, a exemplo das microbacias dos rios São Jorge (Pacheco, et al., 2020), Jacuri (Panza, et al., 2020) e Gavião (Donegá, et al., 2021).

\subsection{Características topográficas}

Os valores de altitude variam de 234 a 458 m, com valor médio de $304 \mathrm{~m}$ (Figura 2), e amplitude altimétrica de $224 \mathrm{~m}$. Se considerar que a região tem uma temperatura média anual de $24^{\circ}$ (SEDAM, 2012), e que a temperatura reduz $0,44^{\circ} \mathrm{C}$ a cada $100 \mathrm{~m}$ de ascensão vertical (Blum, Roderjan \& Galvão, 2011), pode-se deduzir que a microbacia tem uma faixa de temperatura de 23,01 a $24,99^{\circ} \mathrm{C}$.

A altitude influencia a temperatura, precipitação e a evapotranspiração (Villela \& Mattos, 1975), e pode ser utilizada como indicador para uma pré-seleção de espécies agrícolas e florestais de interesse econômico. Na faixa de altitude da microbacia do rio Paraíso podem ser encontradas pelo menos 58 espécies, como pode ser observado no trabalho de Bourke (2010): abacate (Persea americana), abóbora-cheirosa (Cucurbita moschata), agrião (Rorippa nasturtium-aquaticum), amendoim (Arachis hypogaea), arroz (Oryza sativa), banana (Musa sp.), ata (Annona reticulata), batata-doce (Ipomoea batatas), bertalha (Basella alba), brócolis (Brassica oleracea cv. Group Broccoli), cacau (Theobroma cacao), café (Coffea canephora var. robusta), cajá 
manga (Spondias cytherea), cajú (Anacardium occidentale), cana-de-açúcar (Saccharum officinarum), capim cidreira (Cymbopogon citratus), cará (Dioscorea alata), carambola (Averrhoa carambola), chuchu (Sechium edule), coco (Cocos nucifera), couve-flor (Brassica oleracea cv. Group Cauliflower), feijão (Phaseolus vulgaris), fruta-pão (Artocarpus altilis), gengibre (Zingiber officinale), girassol (Helianthus annuus), goiaba (Psidium guajava), graviola (Annona muricata), inhame (Dioscorea esculenta), jaca (Artocarpus heterophyllus), jambo vermelho (Syzygium malaccense), laranja (Citrus sinensis), lima (Citrus aurantifolia), limão (Citrus limon), mamão (Carica papaya), mamona (Ricinus communis), mandioca (Manihot esculenta), manga (Mangifera indica), maracujá-açú (Passiflora quadrangularis), maracujá-amarelo (Passiflora edulis f. flavicarpa), melancia (Citrullus lanatus), melão (Cucumis melo), milho (Zea mays), pepino (Cucumis sativus), pimenta-do-reino (Piper nigrum), pimentamalagueta (Capsicum frutescens), pimentão (Capsicum annuиm cv. group Grossum), pinha (Annona squamosa), pitanga (Eugenia uniflora), quiabo (Abelmoschus esculentus), rabanete (Raphanus sativus cv. group Small Radish), romã (Punica granatum), salsa (Petroselinum crispum), seringueira (Hevea brasiliensis), soja (Glycine max), taioba (Xanthosoma sagittifolium), taro (Colocasia esculenta), tomate (Lycopersicon esculentum) e urucum (Bixa orellana). Em face ao exposto, observa-se elevado potencial para o desenvolvimento da agricultura e para a sustentabilidade financeira dos estabelecimentos agropecuários privados da região em estudo. 
Figura 2. Altitude da microbacia do rio Paraíso, Amazônia Ocidental, Brasil.

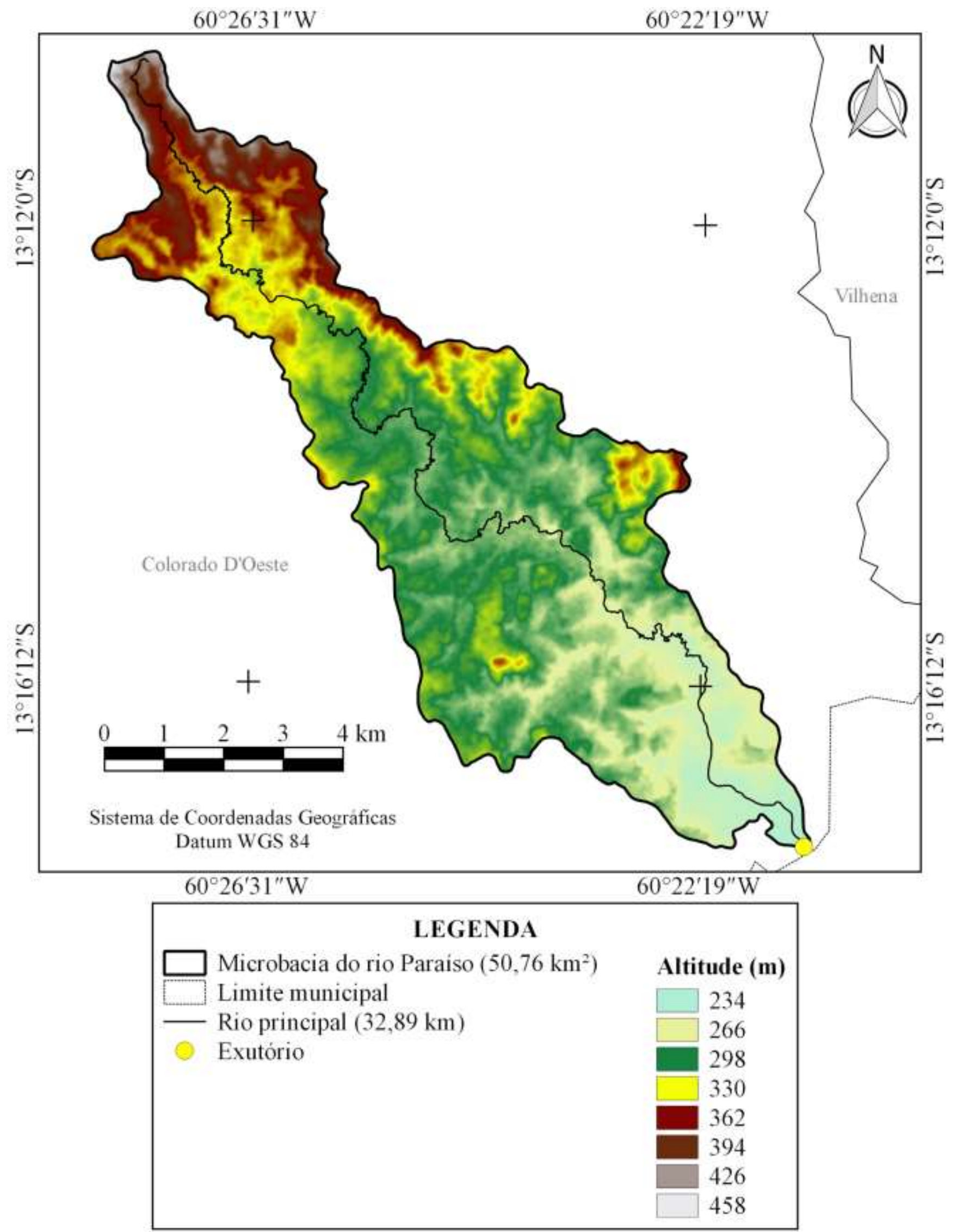

Fonte: Autores. 
A diversidade de espécies de interesse econômico possibilita a implantação de sistemas consorciados, reduzindo o risco financeiro, geralmente atrelado à suscetibilidade de mercado nos sistemas de monocultivo. Em trabalho realizado por Barbosa et al. (2016), por exemplo, constatou-se que o sistema de cultivo diversificado pode ocasionar acréscimos de até 50\% na renda mensal do produtor em relação ao sistema de monocultivo com café. Estes mesmos autores relatam que, na visão dos agricultores, a atividade cafeeira possui muitos riscos e baixa estabilidade de mercado, e essa instabilidade pode ser compensada em parte com a diversificação da produção no mercado da região (ex: comercialização de hortaliças).

Ao analisar a declividade da paisagem, constatou-se que a microbacia tem relevos planos a montanhosos, com maior abrangência das classes ondulado (43,64\%) e suave ondulado (36,54\%) (Figura 3). A declividade do terreno influencia a velocidade do escoamento superficial e, consequentemente, as perdas de solo por erosão hídrica (Bertoni \& Lombardi Neto, 2014). De acordo com Lepsch et al. (2015), o escoamento superficial é lento a muito lento em relevo plano, contudo, a velocidade do escoamento aumenta com a elevação da declividade, chegando a ser considerado muito rápido no relevo escarpado. Portanto, é recomendado a adoção de práticas de manejo conservacionista do solo nos estabelecimentos agropecuários privados, principalmente nas regiões mais íngremes.

As práticas de manejo conservacionista podem ser de caráter edáfico, mecânico ou vegetativo, e visam manter ou melhorar a fertilidade do solo, reduzir o escoamento superficial, diminuir as perdas de solo, matéria orgânica e nutrientes, favorecer a infiltração de água no solo, abastecer o lençol freático e aumentar a produtividade das culturas (Bertoni \& Lombardi Neto, 2014). De acordo com Zonta et al. (2012), podem ser classificadas como práticas de manejo de caráter edáfico a calagem, adubações (química, orgânica e verde) e o controle queimadas, de caráter vegetativo o florestamento, reflorestamento, pastagem, plantas de cobertura, cultivo em contorno, rotação de cultura, plantio em faixas, capina alternada, plantio direto, cobertura morta, ceifa de plantas daninhas e cordões de vegetação, e de caráter mecânico o terraceamento. Logo, existem vários tipos de manejo que podem ser combinados de acordo com as características de declividade em cada região e condições financeiras do interessado.

A microbacia tem regiões com diferentes níveis de influência a propagação de incêndios, classificados como baixo, moderado, alto, muito alto e extremamente alto, e abrangem 78,53,16,73, 3,88, 0,79 e 0,08\% da área total da microbacia, respectivamente. A predominância das classes baixa e moderada influência a propagação de incêndios também foram observadas em outras microbacias localizadas no estado de Rondônia, como as microbacias dos rios Tamarupá (Vendruscolo, et al., 2021), Gavião (Donegá, et al., 2021), Tinguí (Santos, et al., 2019) e Três Galhos (Silva, et al., 2021). Essa é uma característica desejável em estabelecimentos agropecuários privados, tendo em vista que existe menor probabilidade de incêndios acidentais ocasionarem danos aos cultivos e estruturas físicas.

Com relação ao potencial da região para a mecanização agrícola, constata-se que a microbacia tem $24 \%$ da área classificada como extremamente apta, 34,20\% muito apta, 20,31\% apta, 11,47\% moderadamente apta, e apenas 10,03\% não apta. Resultados semelhantes foram observados nas microbacias Alto Rio Escondido (Vendruscolo, et al., 2020a), Médio Rio Escondido (Vendruscolo, et al., 2020b), Gavião (Donegá, et al., 2021), Três Galhos (Silva, et al., 2021), Mutum (Souza, et al., 2021) e Jacuri (Panza et al., 2021), e explicam porque o agronegócio tem se desenvolvido bem na região. Os municípios onde estão inseridas as microbacias citadas estão entre os principais produtores de soja do estado de Rondônia (Pereira \& Kahil, 2010). 
Figura 3. Relevo da microbacia do rio Paraíso, Amazônia Ocidental, Brasil.

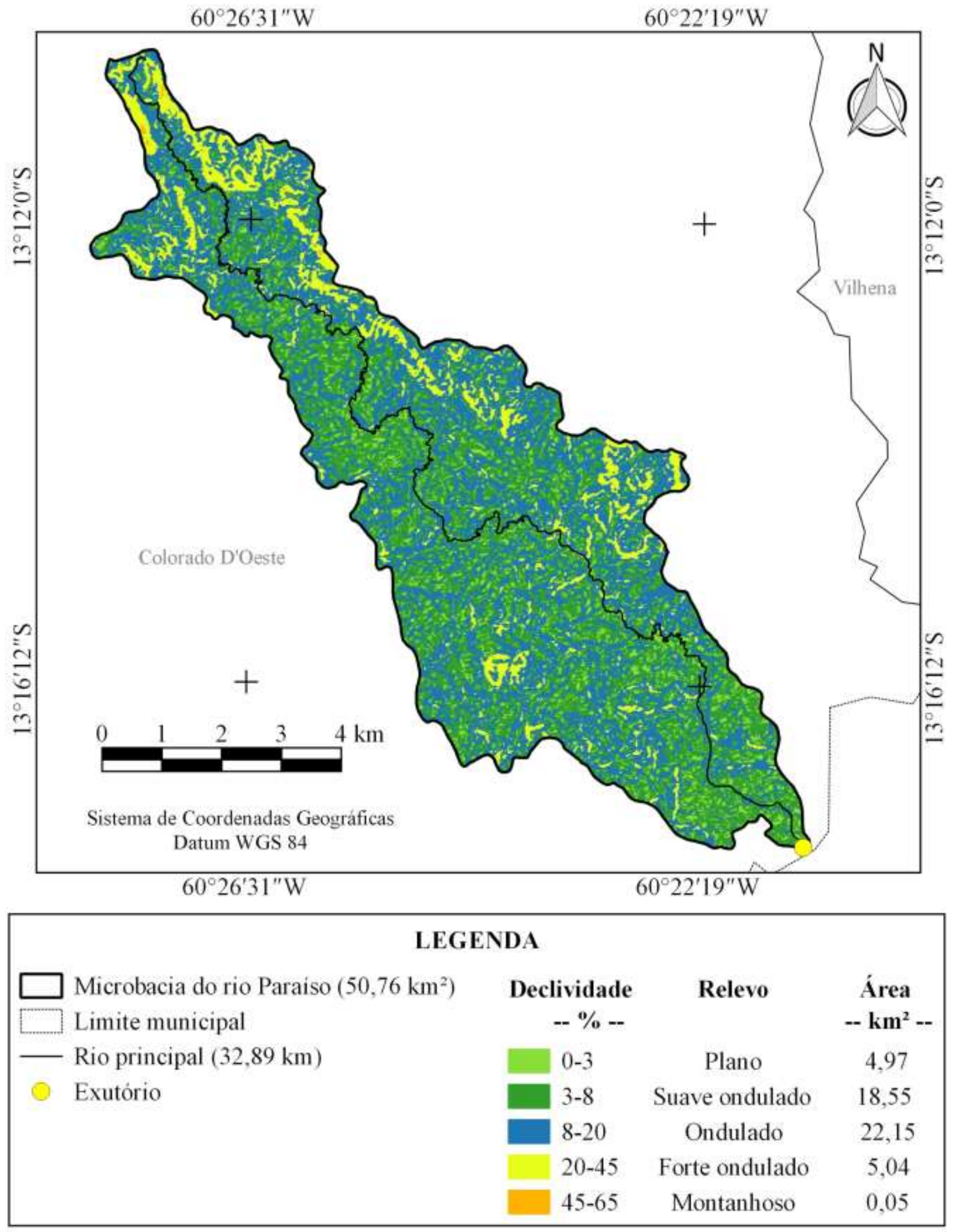

Fonte: Autores. 


\subsection{Características hidrográficas}

A microbacia do rio Paraíso tem rede de drenagem de 179,37 km, padrão de drenagem dendrítico de $5^{\text {a }}$ ordem (Figura 4), 9,50 nascentes $\mathrm{km}^{-2}$ (Figura 5), densidade de drenagem de $3,53 \mathrm{~km} \mathrm{~km}^{-2}$, coeficiente de manutenção de 283,0 $\mathrm{m}^{2} \mathrm{~m}^{-1}$, índice de sinuosidade de $47,73 \%$ e tempo de concentração de $6,68 \mathrm{~h}$.

Os padrões dendríticos são muito comuns no estado de Rondônia, como pode ser observado nas microbacias Alto Rio Escondido (Vendruscolo, et al., 2020a), Médio Rio Escondido (Vendruscolo, et al., 2020b), Enganado (Moreto, et al., 2019), Jacuri (Panza, et al., 2020), Tinguí (Santos, et al., 2019), Tamarupá (Vendruscolo, et al., 2021) e Manicoré (Vendruscolo, et al., 2019). Esse tipo de padrão é formado devido à homogeneidade horizontal da rocha (ex: granito e gnaisse) ou material não consolidado, a qual permite que a erosão se desenvolva de forma similar em todas as direções (Earle \& Panchuk, 2019).

O número de ordem dos rios denota que a região tem um rio com tamanho médio e elevado potencial para habitação de peixes (Tabela 3). A maior diversidade de comunidade aquática se desenvolve em rios médios, com 3 a 5 ordens de drenagem, devido a maior variação da temperatura (Vannote, et al., 1980), portanto, a microbacia do rio Paraíso tem características hidrográficas interessantes que incentivam a realização de estudos da ictiofauna aquática.

A densidade de nascentes de 9,50 nascentes $\mathrm{km}^{-2}$ é considerada alta, enquanto que a densidade de drenagem de 3,53 km $\mathrm{km}^{-2}$ é muito alta (Tabela 3), assim como o observado na microbacia do Alto Rio Escondido (Vendruscolo, et al, 2020a), localizada na bacia do rio Guaporé. Tais parâmetros estão diretamente relacionados com a declividade da paisagem (Vendruscolo, et al., 2020a; Vendruscolo, et al., 2020b). O aumento da declividade favorece a erosão hídrica (Bertoni \& Lombardi Neto, 2014), elevando a probabilidade de formação de canais que tendem a se aprofundar até o lençol freático (Guerra, 1997), e, consequentemente, a formação de novas nascentes e cursos d'água. Logo, estes resultados indicam que a microbacia tem alta capacidade de gerar novos cursos d'água e elevado potencial hídrico, havendo a necessidade de um planejamento mais rígido para a manutenção da quantidade e qualidade de água.

O coeficiente de manutenção de $283,0 \mathrm{~m}^{2} \mathrm{~m}^{-1}$ denota que é necessário uma área maior para a manutenção dos recursos hídricos na microbacia do rio Paraíso em comparação com às microbacias Alto Rio Escondido (Vendruscolo, et al., 2020a), Médio Rio Escondido (Vendruscolo, et al., 2020b) e Três Galhos (Silva, et al., 2021), cujos valores são 234, 246 e 254,5 m² m 1 , respectivamente.

$\mathrm{O}$ índice de sinuosidade indica que o canal principal é sinuoso. Essa característica é muito comum em regiões com padrão de drenagem dendrítico, como pode ser verificado nas microbacias dos rios Tinguí (Santos, et al., 2019), Manicoré (Vendruscolo, et al., 2019), Três Galhos (Silva, et al., 2021), Tamarupá (Vendruscolo, et al., 2021) e D’Alincourt (Silva, et al., 2019). Esse tipo de canal tem um fluxo hídrico mais lento em comparação com um canal retilíneo (Villela \& Mattos, 1975), por apresentarem maiores quantidades de barreiras físicas, incluindo fragmentos lenhosos advindos da vegetação marginal, que se acumulam nos meandros, formando microhabitats que são utilizados como abrigo contra predadores por muitas espécies de peixes (Matthews, 2003 apud Silva, Melo \& Vênere, 2007). Logo, recomendam-se estudos voltados à identificação da ictiofauna nesta microbacia, para melhor entendimento da complexidade do ecossistema aquático da região.

O tempo de concentração na microbacia Paraíso $(6,68$ h) é superior aos observados nas microbacias dos rios Mutum (1,78 h) (Souza, et al., 2021), Três Galhos (2,28 h) (Silva, et al., 2021) e Gavião (2,74 h) (Donegá, et al., 2021). A diferença no tempo de concentração está associada principalmente ao comprimento dos canais principais, visto que tem-se a seguinte ordem de grandeza: Mutum $(6,52 \mathrm{~km})<$ Três Galhos $(12,4 \mathrm{~km})<$ Gavião $(26,41 \mathrm{~km})<$ Paraíso $(32,89$ km). 
Figura 4. Rede de drenagem e ordem dos rios na microbacia do rio Paraíso,

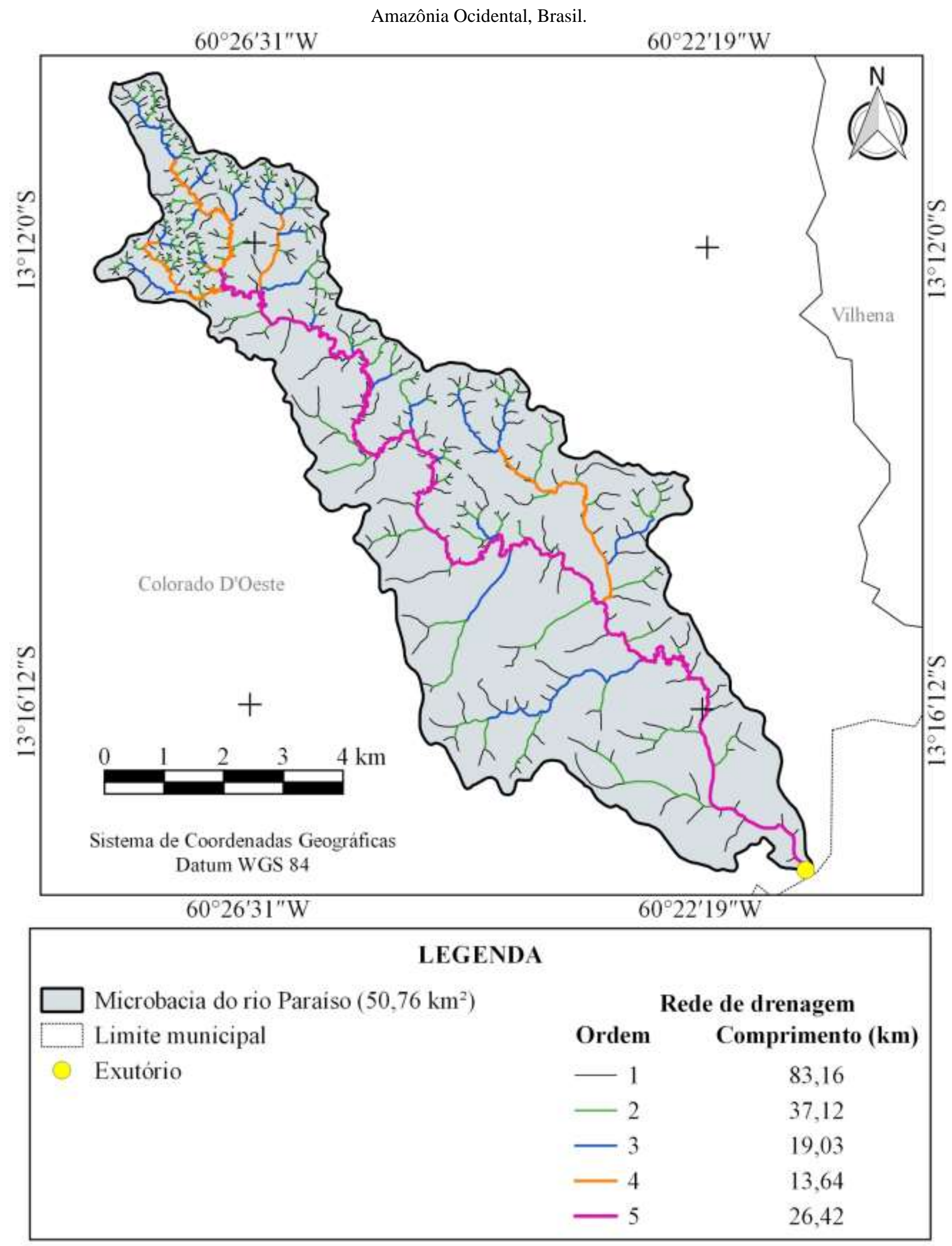

Fonte: Autores. 
Figura 5. Distribuição espacial das nascentes na microbacia do rio Paraíso,

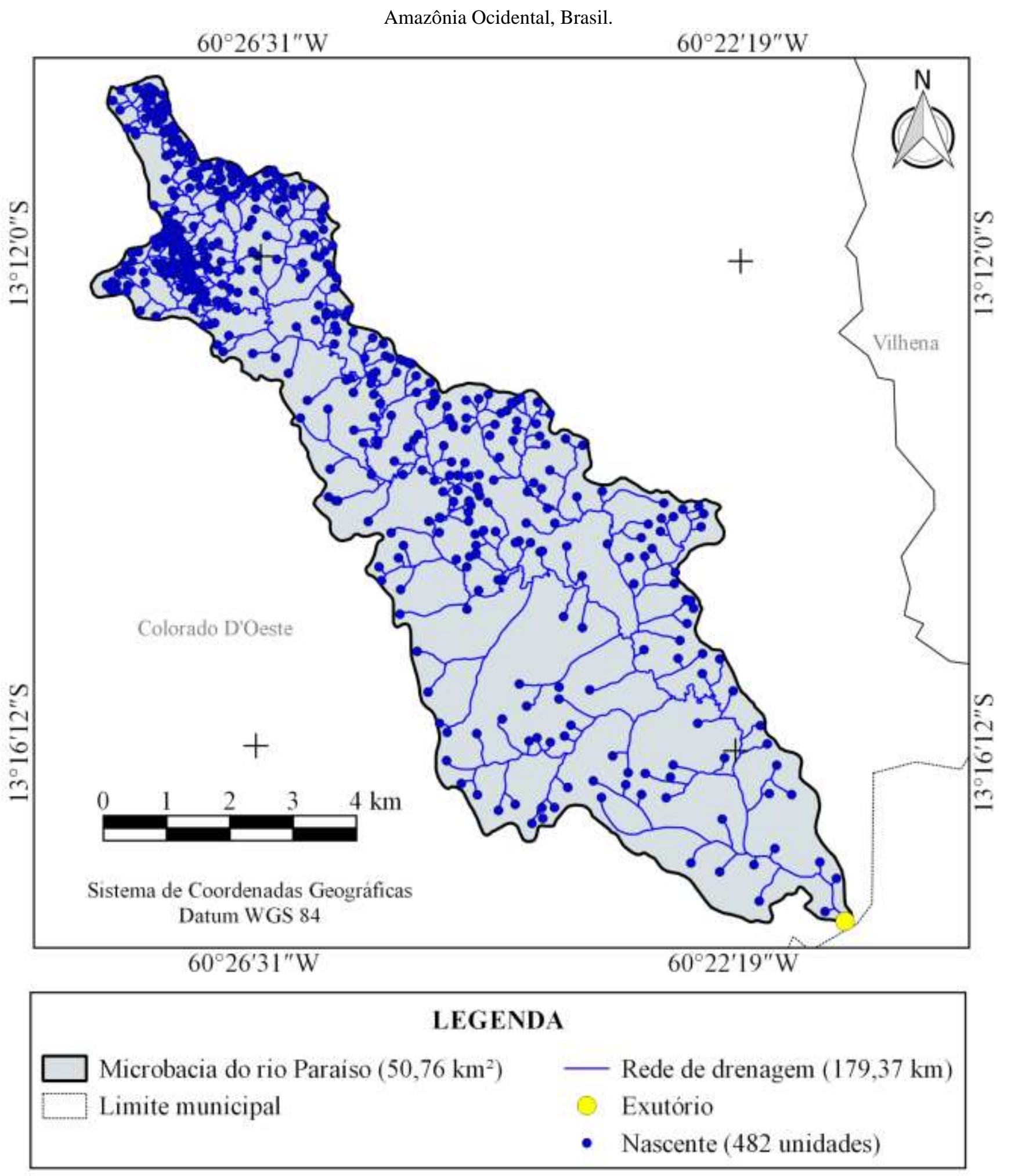

Fonte: Autores.

\subsection{Dinâmica da cobertura do solo na microbacia (1984 e 2020)}

A cobertura do solo com floresta nativa foi reduzida ao longo de 36 anos, tanto na microbacia quanto na zona ripária, restando apenas 19,29 e 34,08\% da área total destas regiões, respectivamente (Figuras 6 e 7). A principal causa destas reduções 
estão associadas ao crescimento agropecuário da região, que passou de 25,06 para 80,32\% da área da microbacia entre os anos de 1984 e 2020, e de 20,55 para 64,21\% na zona ripária, para o mesmo período (Figuras 6 e 7).

Figura 6. Dinâmica da cobertura na microbacia Paraíso, Amazônia Ocidental, Brasil, nos anos de 1984 e 2020.

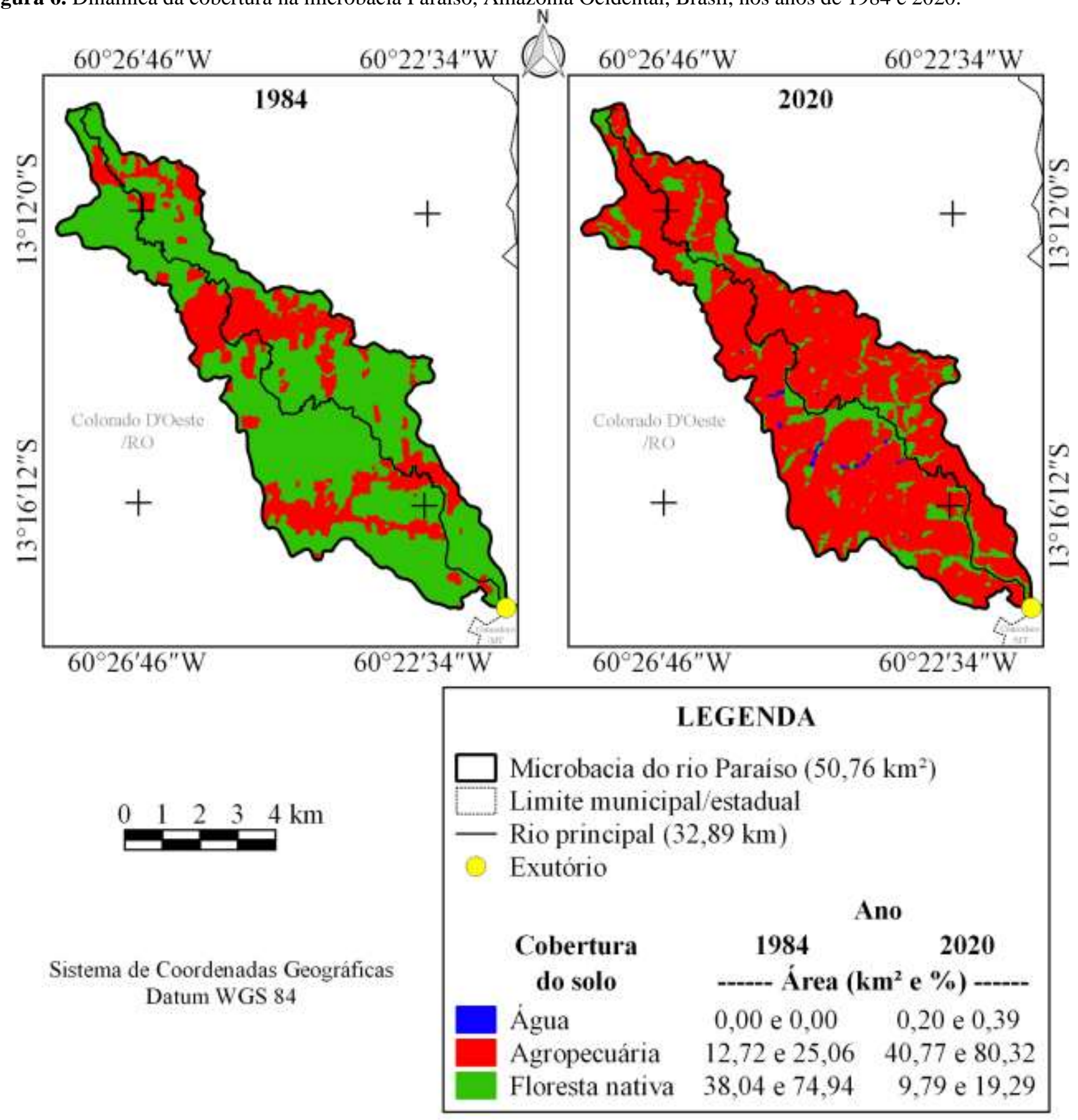

Fonte: Autores. 
Figura 7. Dinâmica da cobertura na zona ripária da microbacia Paraíso, Amazônia Ocidental, Brasil, nos anos de 1984 e 2020.

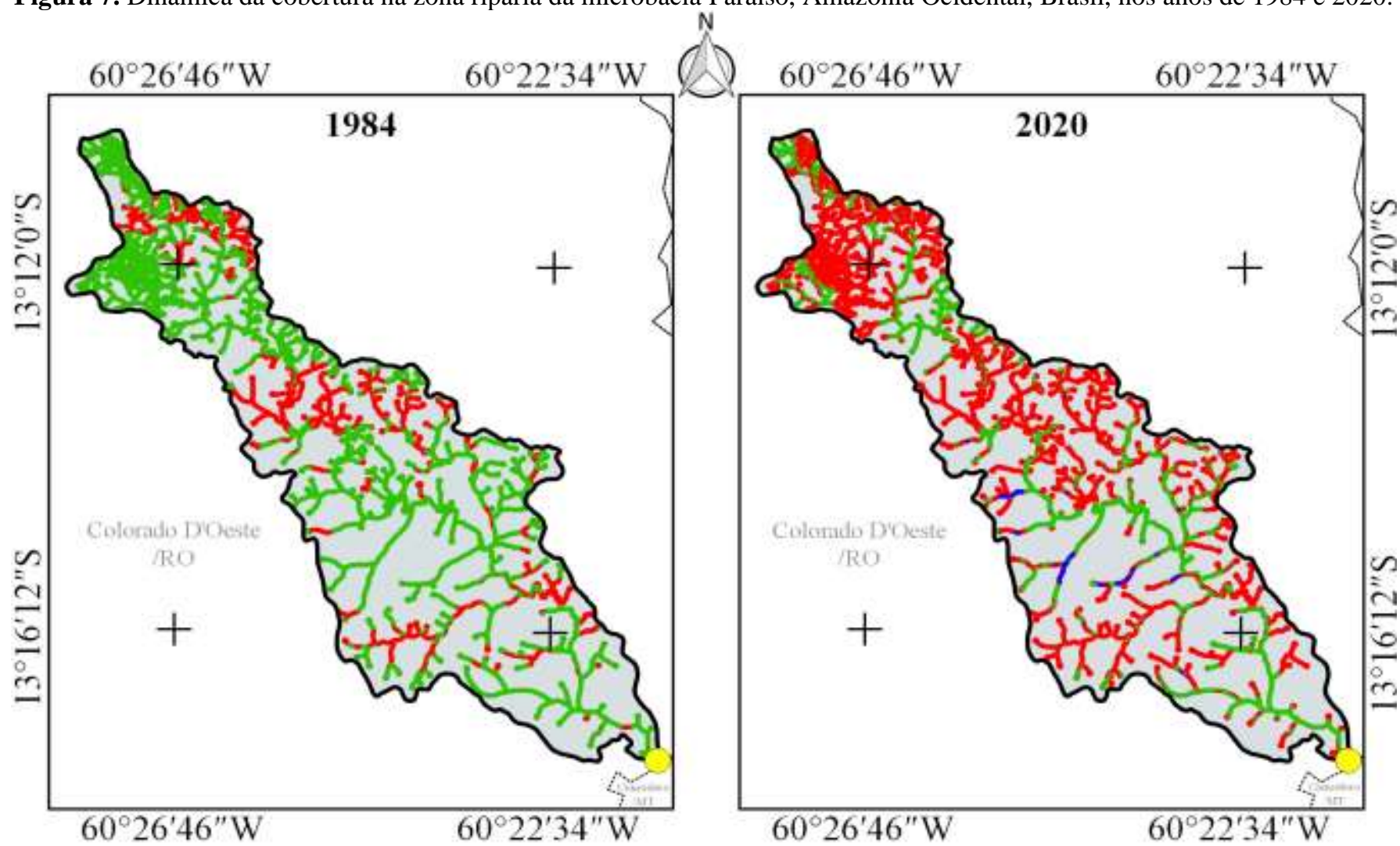

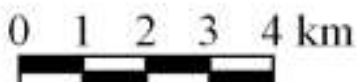

Sistema de Coordenadas Geográficas Datum WGS 84

\section{LEGENDA}

Microbacia do rio Paraiso $\left(50,76 \mathrm{~km}^{2}\right)$

Limite municipal/estadual

\section{Exutório}

\section{Ano}

Cobertura do solo

Água

Agropecuária

Floresta nativa

\begin{tabular}{cc}
$\mathbf{1 9 8 4}$ & $\mathbf{2 0 2 0}$ \\
\hdashline- Área $\left(\mathbf{k m}^{\mathbf{2}} \mathbf{e} \%\right)--$ \\
0,00 e 0,00 & 0,20 e 1,71 \\
2,40 e 20,55 & 7,50 e 64,21 \\
9,28 e 79,45 & 3,98 e 34,08
\end{tabular}

Fonte: Autores.

O avanço da agropecuária ao longo dos anos representa um desenvolvimento econômico na região, contudo, ressaltase que é necessário manter uma proporção adequada de floresta nativa em cada porção de relevo, para manter a qualidade e a disponibilidade de água para a atual e futuras gerações, e assim o desenvolvimento sustentável da região. Em trabalho realizado por Tambosi et al. (2015), constatou-se que a cobertura florestal tem funções eco-hidrológicas distintas de acordo com a posição que ocupa no relevo, com recarga dos aquíferos no topo dos morros, redução do escoamento superficial e contenção de erosões hídricas nas encostas, proteção da qualidade da água nas zonas ripárias e elementos auxiliares nos intervales. Portanto, a manutenção da floresta nativa em áreas de preservação permanente (APP) e Reservas Legais (RL), e a inserção do componente arbóreo nos sistemas de produção, a exemplo de sistemas agroflorestais, silvipastoris e agrossilvipastoris, são práticas extremamente recomendadas para os estabelecimentos agropecuários que compõe a microbacia do rio Paraíso. 


\section{Conclusão}

A microbacia do rio Paraíso tem forma alongada, baixa suscetibilidade a enchentes, altitudes entre 234 e 458 m, predomínio de relevo ondulado $(43,68 \%)$, rio de porte médio, padrão de drenagem dendrítico, rios de $5^{\mathrm{a}}$ ordem, alta densidade de nascentes, densidade de drenagem muito alta, canal principal sinuoso, baixo coeficiente de manutenção e alto tempo de concentração.

No período de 1984 a 2020, ocorreu o avanço da agropecuária sobre as áreas de floresta nativa, chegando a ocupar $80,32 \%$ da área da microbacia e $64,21 \%$ da área de zona ripária no último ano.

As características da paisagem da microbacia do rio Paraíso denotam que a região tem elevado potencial para o desenvolvimento de sistemas agropecuários, inclusive com mecanização agrícola, contudo são recomendadas adoções de práticas de manejo conservacionista do solo e da água, recuperar e manter a floresta nativa na zona ripária e reservas legais, e integrar o componente arbóreo nos sistemas econômicos por meio de sistemas agroflorestais, silvipastoris e/ou agrossilvipastoris.

Recomendam-se estudos para analisar a quantidade e a qualidade da cobertura florestal nas áreas de Reservas Legais, com o objetivo de complementar as informações necessárias ao desenvolvimento de estratégias visando a manutenção da qualidade e quantidade de recursos hídricos.

\section{Referências}

Alvares, C. A, Stape, J. L., Sentelhas, P. C., Gonçalves, L. M., \& Sparovek, G. (2013). Köppen's climate classification map for Brazil. Meteorologische Zeitschrift, 22(6), 711-728. 10.1127/0941-2948/2013/0507

ASF - Alaska Satellite Facility (2017). Imagem altimétrica. https://www.asf.alaska.edu/

Barbosa, P. J., F. Mendonça, J. C. A., Casarotto, E. L., Machado, R. R., Almeira, V. L., \& Vitorino Filho, V. A. (2016). A importância da diversificação agrícola como complemento de renda familiar na região de Manhuaçu-MG. Revista do Centro de Ciências Economia e Informática, 20(35), 1-11.

Beltrame, A. V. (1994). Diagnóstico do meio ambiente físico de bacias hidrográficas: modelo de aplicação. Florianópolis: Universidade Federal de Santa Catarina.

Bertoni, J., \& Lombardi Neto, F. (2014). Conservação do solo. Editora Icone.

Blum, C. T., Roderjan, C. V., \& Galvão, F. (2011). O clima e sua influência na distribuição da floresta ombrófila densa na Serra da Prata, Morretes, Paraná. Floresta, 41(3), 589-598. 10.5380/rf.v41i3.24052

Bourke, R. M. (2010). Altitudinal limits of 230 economic crop species in Papua New Guinea. In: Haberle, S. G., Stevenson, J., \& Prebble, M. (eds). Altered Ecologies: Fire, Climate and Human Influence on Terrestrial Landscapes. Canberra: The Australian National University.

Brasil. (2012). Lei $n^{o} 12.651$, de 25 de maio de 2012 - Dispõe sobre a proteção da vegetação nativa. http://www.planalto.gov.br/ccivil_03/_ato20112014/2012/lei/112651.htm

Castro, C. N. (2013). A agropecuária na região Norte: oportunidades e limitações ao desenvolvimento. Instituto de Pesquisa Econômica Aplicada.

Christofoletti, A. (1980). Geomorfologia. (2a ed.). Edgard Blucher.

Cherem, L. F. S., Faria, S. D., Zancopé, M. H. C., Sordi, M. V., Nunes, E. D., \& Rosa, L. E. (2020). Análise morfométrica em bacias hidrográficas. In. Magalhães Júnior, A. P., \& Barros, L. F. P. Hidrogeomorfologia: formas, processos e registros sedimentares fluviais. Bertrand Brasil.

Donegá, M. V. B., Souza, T. W. S., Lima, M. M., Panza, M. R., Pacheco, F. M. P., Saraiva, J. G., Cavalheiro, W. C. S., \& Vendruscolo, J. (2021). Caracterização hidrogeomorfométrica da microbacia do rio Gavião, Amazônia Ocidental, Brasil. Research, Society and Development, 10(1), 1-14. 10.33448/rsd-v10i1.11844

Earle, E., \& Panchuk, K. (2019). Physical Geology. (2a ed.), Victoria, B.C.: BCcampus.

Fairfull, S., \& Witheridge, G. (2003). Why do Fish Need to Cross the Road? Fish Passage Requirements for Waterway Crossings. NSW Fisheries.

Franca, R. R. (2015). Climatologia das chuvas em Rondônia - período 1981-2011. Revista Geografias, 11(1), 44-58. https://periodicos.ufmg.br/index.php/geografias/article/view/13392/10624

Guerra, A. J. T. (1997). Ravinas: processo de formação e desenvolvimento. Anuário do Instituto de Geociências, $20,9-26$.

Höfig, P., \& Araujo-Junior, C. F. (2015). Classes de declividade do terreno e potencial para mecanização no estado do Paraná. Coffee Science, 10(2), 195-203. https://www.researchgate.net/publication/277597916_classes_de_declividade_do_terreno_e_potencial_para_mecanizacao_no_estado_do_parana

Horton, R. E. (1932). Drainage basin characteristics. Transactions, American Geophysical Union, 13(1), 350-361. 
INCRA - Instituto Nacional de Colonização e Reforma Agrária (2019). Acervo fundiário. INCRA. http://acervofundiario.incra.gov.br/acervo/acv.php.

INPE - Instituto Nacional de Pesquisa Espacial. (2020). Catálogo de imagens. INPE. 2020. http://www.dgi.inpe.br/CDSR/

Lepsch, I. F., Espindola, C. R., Vischi Filho, O. J., Hernani, L. C. \& Siqueira, D. S. (2015). Manual para levantamento utilitário e classificação de terras no sistema de capacidade de uso. Sociedade Brasileira de Ciência do Solo. Viçosa-MG, Brasil.

Lima Júnior, J. C., Vieira, W. L., Macêdo, K. G., Souza, S. A., \& Nascimento, F. A. L. (2012). Determinação das características morfométricas da sub-bacia do Riacho Madeira Cortada, Quixelô, CE. VII Congresso Norte-Nordeste de Pesquisa e Inovação. Palmas-TO: Instituto Federal de Educação, Ciência e Tecnologia. p. $1-7$.

Lollo, J. A. (1995). O uso da técnica de avaliação do terreno no processo de elaboração do mapeamento geotécnico: sistematização e aplicação na quadrícula de Campinas. São Carlos: Universidade de São Paulo.

Moreto, R. F., Mira, S. F., Soares, G. S., Santos Junior, N. R. F., Cavalheiro, W. C. S, Vendruscolo, J., \& Rosa, D. M. (2019). Características geométricas, topográficas e hidrográficas da microbacia do rio Enganado, região sul da Amazônia Ocidental. Revista Geográfica Venezolana, especial, 110-124. http://www.saber.ula.ve/handle/123456789/46159

Pacheco, F. M. P., Vendruscolo, J., Ramos, F. H., Rodrigues, A. A. M., Cavalheiro, W. C. S., Hara, F. A. S., Rocha, K. J., \& Silva, G. N. (2020). Caracterização hidrogeomorfométrica da microbacia do rio São Jorge, Rondônia, Brasil. Brazilian Journal of Development, 6(1), 4219-4236. 10.34117/bjdv6n1-301

Panza, M. R., Donegá, M. V. B., Pacheco, F. M. P., Nagao, E. O., Hara, F. A. S., Cavalheiro, W. C. S., \& Vendruscolo, J. (2020). Características da paisagem para manejo dos recursos naturais na microbacia do Rio Jacuri, Amazônia Ocidental, Brasil. Brazilian Journal of Development, 6(12), 101532-101558. $10.34117 /$ bjdv6n12-592

Parvis, M. (1950). Drainage pattern significance in airphoto identification of soils and bedrocks. Photogrammetric Engineering, 16, 387-408.

Ribeiro, L., Koproski, L. P., Stolle, L., Lingnau, C., Soares, R. V., \& Batista, A. C. (2008). Zoneamento de riscos de incêndios florestais para a Fazenda Experimental do Canguiri, Pinhais (PR). Floresta, 38(3), 561-572. 10.5380/rf.v38i3.12430

Romero, V., Formiga, K. T. M., \& Marcuzzo, F. F. N. (2017). Estudo hidromorfológico de bacia hidrográfica urbana em Goiânia/GO. Ciência e Natura, 39(2), 320-340. 10.5902/2179460X26411

Pacheco, F. M. P., Vendruscolo, J., Ramos, F. H., Rodrigues, A. A. M., Cavalheiro, W. C. S., Hara, F. A. S., Rocha, K. J., \& Silva, G. N. (2020). Caracterização hidrogeomorfométrica da microbacia do rio São Jorge, Rondônia, Brasil. Brazilian Journal of Development, 6(1), 4219-4236. 10.34117/bjdv6n1-301

Parvis, M. (1950). Drainage pattern significance in airphoto identification of soils and bedrocks. Photogrammetric Engineering, 16, 387-408.

Pereira, A. S., Shitsuka, D. M., Parreira, F. J., \& Shitsuka, R. (2018). Metodologia da Pesquisa Científica. Universidade Federal de Santa Maria. https://repositorio.ufsm.br/bitstream/handle/1/15824/Lic_Computacao_Metodologia-Pesquisa-Cientifica.pdf?sequence=1

Pereira, M. F. V. \& Kahil, S. P. (2010). A lógica corporativa do uso do território em Rondônia: o agronegócio da soja na região de Vilhena. Campo-Território: Revista de Geografia Agrária, 5(10), 288-311.

Santos, A. M., Targa, M. S., Batista, G. T., \& Dias, N. W. (2012). Análise morfométrica das sub-bacias hidrográficas Perdizes e Fojo no município de Campos do Jordão, SP, Brasil. Revista Ambiente \& Água, 7(3), 195-211. 10.4136/1980-993X

Santos, L. P., Rosa, D. M., Cavalheiro, W. C. S., Vendruscolo, J., Rosell, E. C. F., Biggs, T., \& Stachiw, R. (2019). Hidrogeomorfometria e índice de desmatamento da microbacia do rio Tinguí, Amazônia Ocidental, Brasil. Revista Geográfica Venezolana, 40-56. http://www.saber.ula.ve/handle/123456789/46154.

Santos, R. D., Lemos, R. C., Santos, H. G., Ker, J. C., Anjos, L. H. C. \& Shimizu, S. H. (2013). Manual de descrição e coleta de solo no campo. Viçosa-MG: Sociedade Brasileira de Ciência do Solo.

SEDAM - Secretaria de Estado do Desenvolvimento Ambiental. (2002). Atlas Geoambiental de Rondônia. SEDAM.

SEDAM - Secretaria de Estado do Desenvolvimento Ambiental. (2012). Boletim climatológico de Rondônia - 2010. SEDAM.

Silva, A. F., Tronco, K. M. de Q., Vendruscolo, J., Oliveira, J. N. de, Cavalheiro, W. C. S., Rosa, D. M., \& Stachiw, R. (2019). Geoprocessamento aplicado a hidrogeomorfometria e índice de desflorestamento na microbacia do rio D’Alincourt, Amazônia Ocidental, Brasil. Revista Geográfica Venezolana, especial, 210-225.

Silva, C. J., Sousa, K. N. S., Ikeda-Castrillona, S. K., Lopes, C. R. A., Nunes, J. R. S., Carniello, M. A., Mariotti, P. R., Lazaro, W. L., Morini, A., Zago, B. W., Façanha, C. L., Albernaz-Silveira, R., Loureiro, E., Viana, I. G., Oliveira, R. F., Cruz, W. J. A., Arruda, J. C., Sander, N. L., Freitas Junior, D. S., Pinto, V. R., Lima, A. C., \& Jongmand, R. H. G. (2015). Biodiversity and its drivers and pressures of change in the wetlands of the Upper Paraguay-Guaporé Ecotone, Mato Grosso (Brazil). Land Use Policy, 47, 163-178. 10.1016/j.landusepol.2015.04.004

Silva, E. C., Praia, W. M., Santos, A. S., Cardoso, L. A. P., Hara, F. A. S., Cavalheiro, W. C. S., \& Vendruscolo, J. (2021). Características hidrogeomorfométricas da microbacia Três Galhos, Amazônia Ocidental, Brasil. Research, Society and Development, 10(2), 1-17, 2021. 10.33448/rsd-v10i2.12408

Silva, E. F., Melo, C. E., \& Vênere, P. C. (2007). Fatores que influenciam a comunidade de peixes em dois ambientes no baixo Rio das Mortes, Planície do Bananal, Mato Grosso, Brasil. Revista Brasileira de Zoologia, 24(2), 482-492. 10.1590/S0101-81752007000200029

Silva, Q. D. (2012). Mapeamento geomorfológico da Ilha do Maranhão. Universidade Estadual Paulista.

Soares, G. S., Santos Júnior, N. R. F., Mira, S. F., Moreto, R. F., Cavalheiro, W. C. S., Vendruscolo, J., \& Rosa, D. M. (2019). Uso de plataforma SIG na caracterização morfométrica da microbacia do rio Santa Teresinha, Amazônia Ocidental, Brasil. Revista Geográfica Venezolana, especial, 84-95. http://www.saber.ula.ve/handle/123456789/46157 
Souza, T. W. S., Lima, M. M., Saraiva, J. G., Pacheco, F. M. P., Donegá, M. V. B., Panza, M. R., Cavalheiro, W. C. S., \& Vendruscolo, J. (2021). Análise hidrogeomorfométrica da microbacia do rio Mutum: informações para auxiliar o manejo de recursos hídricos na Amazônia Ocidental. Research, Society and Development, 10(2), 1-17 10.33448/rsd-v10i2.12448

Strahler, A. N. (1954). Quantitative geomorphology of erosional landscapes. XIX International Geologic Congress, 13(15), 341-354.

Targa, M. S., Batista, G. T., Diniz, H. D., Dias, N. W., \& Matos, F. C. (2012). Urbanização e escoamento superficial na bacia hidrográfica do Igarapé Tu cunduba, Belém, PA, Brasil. Revista Ambiente \& Água, 7(2), 120-142. 10.4136/1980-993X

Tambosi, L., Vidal, M. M., Ferraz, S. F. B., \& Metzger, J. P. (2015). Funções eco-hidrológicas das florestas nativas e o Código Florestal. Estudos Avançados, 29(84), 151-162. 10.1590/S0103-40142015000200010

Vannote, R. L., Minshall, G. W., Cummins, K. W., Sedell, J. R., \& Cushing, C. E. (1980). The river continuum concept. Canadian Journal of Fisheries and Aquatic Sciences, 37, 130-137.

Vendruscolo, J., Araujo, M. G. S., Ferreira, L. R., Rosa, D. M., \& Hara, F. A. S. (2021). O uso de geotecnologias na caracterização geométrica, topográfica e hidrográfica da microbacia do rio Tamarupá, Amazônia Ocidental, Brasil. Brazilian Journal of Development, 7(1), 4245-4264. 10.34117/bjdv7n1-286

Vendruscolo, J., Cavalheiro, W. C. S., Rosa, D. M., Stachiw, R., Vendruscolo, R., Siqueira, A. S., \& Biggs, T. (2019). Hidrogeomorfometria e desmatamento na microbacia do rio Manicoré, Amazônia Ocidental, Brasil. Revista Geográfica Venezolana, especial, 226-241. http://www.saber.ula.ve/handle/123456789/46171

Vendruscolo, J., Pacheco, F. M. P., Ramos, H. F., Cavalheiro, W. C. S., \& Rodrigues, A. A. M. (2020a). Hidrogeomorfometria da microbacia Alto Rio Escondido: informações para auxiliar o manejo dos recursos naturais na Amazônia ocidental. Brazilian Journal of Development, 6(3), 9709-9730. 10.34117/bjdv6n3-011

Vendruscolo, J., Pacheco, F. M. P., Rodrigues, A. A. M., Ramos, H. F., Rosa, D. M. \& Cavalheiro, W. C. S. (2020b). Características morfométricas da microbacia do Médio Rio Escondido, Amazônia Ocidental, Brasil. Brazilian Journal of Development, 6(1), 565-585. 10.34117/bjdv6n1-040

Villela, S. M., \& Mattos, A. (1975). Hidrologia aplicada. McGraw-Hill.

Zonta, J. H., Sofiatti, V., Costa, A. G. F., Silva, O. R. R. F., Bezerra, J. R. C., Silva, C. A. D., Beltrão, N. E. M., Alves, A., Cordeiro Júnior, A. F., Cartaxo, W. V., Ramos, E. N., Oliveira, M. C., Cunha, D. S., Mota, M. O. S., Soares, A. N., \& Barbosa, H. F. (2012). Práticas de Conservação de Solo e Água. Empresa Brasileira de Pesquisa Agropecuária. 